\title{
Subnational estimates of maternal mortality in Nigeria: Analysis of female siblings' survivorship histories.
}

Opeyemi Oluwatosin Babajide ( $\sim$ opeyemilatona@gmail.com )

University of Ibadan

Joshua Odunayo Akinyemi

University of Ibadan

Olusola Ayeni

University of Ibadan

\section{Research Article}

Keywords: Maternal Mortality, Small area estimation, Nigeria Demographic and Health Surveys, Empirical Bayesian

Posted Date: December 22nd, 2021

DOI: https://doi.org/10.21203/rs.3.rs-1190088/v1

License: (c) (i) This work is licensed under a Creative Commons Attribution 4.0 International License. Read Full License 
1 Title: Subnational estimates of maternal mortality in Nigeria: Analysis of female

2

4

5 Word count:

\section{First Author / Corresponding}

7 Author:

8

9

10

11

12

13

14

15

16

17

18

19

20

21

22

23

24

25

\section{Co- Authors:}

Names

Academic degrees

Affiliations

Names

Academic degrees

Affiliations

E-mail addresses

10 keywords: Maternal Mortality, Small area estimation, Nigeria Demographic and Health Surveys, Empirical Bayesian

PhD (Ibadan)

E-mail addresses_odunjoshua@gmail.com

Opeyemi Oluwatosin Babajide B.Sc.(Ib), M.Sc. Medical Statistics (Ibadan), PhD (Ib) Department of Epidemiology and Medical Statistics, University of Ibadan opeyemilatona@gmail.com 08038108825
Department of Epidemiology and Medical Statistics, University of Ibadan

Olusola Ayeni

Joshua Odunayo Akinyemi

B.Tech Computer Science (Akure), M.Sc. Medical Statistics (Ibadan), B.Tech Compute

B.Sc. (Ib), M.Sc. Medical Statistics (London), PhD (London)

Department of Epidemiology and Medical Statistics, University of Ibadan

ayenisolaz@yahoo.com 
27 High Maternal Mortality (MM) in Nigeria is further complicated by the lack of reliable

28

29

30

31

32

33

34

35

36

37

38

39

40

41

42

43

44

45

46

47

estimates for subnational levels such as states and geopolitical regions. Disaggregating

maternal mortality estimates by subnational levels is crucial to ensuring policy decisions

and program implementation are adapted to areas with a high burden of mortality. This

study involves a novel adaptation of small area estimation techniques to derive plausible

estimates of levels and trends in Maternal Mortality rates and ratios for states and

geopolitical regions in Nigeria.

METHODS. Survivorship history data of 293,769 female siblings were provided by

114,154 women in the Nigeria Demographic and Health Surveys of 2008, 2013 and 2018.

MM Rates and Ratios were estimated using the Empirical Bayesian technique for small

area demographic estimates. The James-Stein estimator was used to shrink the estimates

closer to the population mean values with 95\% Confidence Interval (Cl).

\section{RESULTS}

Levels of MMRatio were highest in the rural areas, States and regions in Northern

Nigeria. MMRatio was consistently lower in the South West $(2008=281 ; 2013=367$;

2018=392) and higher among the Northern regions of the country, particularly the

North-East $(2008=654 ; 2013=612 ; 2018=901)$ for three consecutive surveys. Over the

three surveys, mortality trends declined about $18 \%$ in the North West and $54.2 \%$ in the

South East region. However, there was a 4.8\% increase in MMRatio for South West

between 2008 to 2018.

\section{CONCLUSIONS}


$48 \quad$ Nigeria has geopolitical and sub-national disparities that pose a burden to the country's

49 maternal health. Since several states in the Northern geopolitical zone still show high

50 maternal mortality, targeted intervention at state levels should be explored to ensure that

51 mothers who need help get it to ensure the sustainable development goals are met. 
52

53 Elevated levels of maternal mortality are a challenge for population health and

54 development. In 1987, the United Nations launched the Safe motherhood initiative (SMI)

55 in Kenya. This initiative was established to reduce death during pregnancy and after

56 childbirth. The SMI aimed to reduce the MM ratio by 50 percent by the year 2000 (1).

57 Several other initiatives such as the Millennium Development Goals (MDGs) and

58 Sustainable Development Goals (SDGs) introduced various programmes targeted at

59 reducing the global level of MM. Despite these efforts, evidence suggests only a modest

60 reduction in maternal mortality in developing countries (2). According to the World Health

61 Organization, 99\% of all maternal mortality occurs in LMIC, and it is endemic in rural areas

62 and poor communities (3). Globally, Nigeria and India rank top on the list of countries

63 with the highest estimated number of maternal deaths according to WHO with an estimate

64 of 67,000 and 35,000 maternal deaths (23\% and $12 \%$ of global maternal deaths)

65 respectively(2). Sub-Saharan Africa as a region has a high MMRatio (MMRatio = 542 in

66 2017). Nigeria with MMRatio $=917$, is the most populous country in SSA and as such

67 contributes largely to the burden of $\mathrm{MM}(2)$.

68 While several analyses of MM trends show that Nigeria is making progress in reducing the

69 maternal mortality rate, the pace remains slow as a woman's chance of dying from

70 pregnancy and childbirth is 1 in 13 and more startling is that most of these deaths are

71 preventable (2). Several doubts have risen about the numbers that have been published

72 as the rates of Maternal Mortality in Nigeria, considering the fluctuation and inconsistency

73 of the figures and the uncertainty of their sources. The difficulty in measurement can be 
attributed rightly to the inadequate recording of adult deaths, misclassification of maternal death, and the relatively rare nature of maternal deaths (4-7). Nigeria, as a country, has an inefficient vital/civil registration system, a challenge several developing countries are battling $(8,9)$. In the absence of a complete vital registration system, which should have been the accurate source of number and causes of deaths, these concerns about the estimates are not outrageous in themselves since estimates are generated by alternate methods based on several assumptions or from health facilities neglecting events that occurred out of the hospitals. Therefore, Nigeria does not only contribute enormously to the high maternal mortality rate in the world but also still has challenges in the measurement of the specific estimates.

Consequently, the various interventions and efforts to reduce maternal deaths and maternal mortality rates cannot be appreciated nor can impact be properly measured, if there are no adequate data and reliable estimates to measure the various performance indicators. Like most LMIC, there are relative inadequacies observed in the information on maternal mortality (MM) in Nigeria. Additionally, without valid estimates for the national and subnational subpopulations, the interventions cannot be targeted accurately to the groups of individuals who need them the most. This can be linked to the recent emphasis on a need to disaggregate data by variables such as socioeconomic status, geographical area, or even sex in the aim to reinforce data monitoring and accountability(10).

The question, therefore, remains, "what is the magnitude of maternal mortality and how is this burden distributed across different states, to ensure the government appropriates the interventions successfully?" There are no generally accepted consistent estimates of 
96 the maternal mortality rate in Nigeria. There seem to be differences in the estimates

97 produced in various studies and used for various purposes (additional table 1). Not only

98 are these figures displaying wide variation and disparity, but they concealed the

99 differentials of these estimates within the different regions, states, and socio-economic

100 groups in respective countries.

101 Several estimates that were provided in the past have been criticized for either being too

102 low or too high (11). Besides, it has been argued that they do not reflect the impact of

103 several interventions that have been implemented for maternal mortality reduction(12).

104 Another obvious inadequacy of the existing estimates for Nigeria is that they refer to the 105 country as a whole: there are no differentials such as urban/rural, geopolitical zones, and 106 administrative entities such as states that are necessary for disaggregated planning 107 purposes. Meanwhile, States are semi-autonomous and empowered to design their 108 policies and programmes. It is therefore essential to have subnational estimates of 109 maternal mortality useful for state-level initiates on maternal health indices. . Therefore, 110 this study involves a novel adaptation of small area estimation techniques to derive 111 plausible estimates of Maternal Mortality rates and ratios for the thirty-six states, six geo112 political regions, rural and urban areas of Nigeria.

\section{Methods}

\section{Data Source}

115 This study is a demographic and statistical analysis of cross-sectional population-based 116 data obtained from the Nigerian Demographic and Health Surveys of 2008, 2013, and 1172018. 
118 For this analysis, the maternal and adult mortality module is also known as the sibling

119 survival module which was added to 2008, 2013, and 2018 Women's Questionnaire was

120 used. The respondents were asked questions about their siblings born to the same

121 biological mother. The name of each of the siblings is provided from the oldest to the

122 youngest, with which the interview proceeds to find more details about each of the

123 siblings. The current age of the siblings is required as well as the marital status, for living

124 siblings. The age at death and year since death is asked for siblings that are reported to be

125 dead. Female siblings who are above the age of 15 are further probed about. The interview

126 asked if the sister died during pregnancy, childbirth, or during the postpartum period. Then

127 MM rates and ratio were derived using the Empirical Bayesian Estimation of MM for states.

128 This method was also adopted by Ahmed \& Hill to generate similar estimates for MM in

129 Bangladesh(13). Selected factors in line with the McCarthy and Maine analytical

130 framework (14) were explored as covariates to get estimates that were being used in the

131 comparison of MM levels across states in Nigeria.

132 In preparing the data for analysis, the period length is captured by computing reference

133 period which is the seven-year period prior the survey, excluding the month of the

134 interview i.e. 0 - 6 years preceding the survey. The Individual sibling respondent dataset

135 was then reconstructed into panel data (person-years) using the varstocases command in

136 SPSS and each reported sibling was counted as an observation and is the unit of analysis

137 from the siblings' history. This reconstructed dataset is labeled as the MM dataset. It has

138 the records of all female siblings reported by the individual women. The data of female

139 siblings who were dead from maternal causes were then used for further analysis. Female 
140 siblings who are reported to have died were assumed to be exposed to the risk of dying

141 for 6 months in their year of death and this was considered in calculating the person-years

142 of exposure. For entries with missing value on the survival of the siblings, it was excluded

143 from the analysis. Age was adjusted for all the estimates generated and sampling weight

144 was taken into consideration for all analyses. The dataset was then disaggregated to the 145 various sub-population which include the 36 states and FCT. This was done using the IBM 146 SPSS Syntax in Version 21.0.

\section{Statistical Analysis}

148 A direct estimator of MMRate was obtained based on sample weights of the information

149 of maternal deaths from the NDHS.

$$
M_{\text {Mate }} \text { direct }=Y_{\text {direct }}=\sum \frac{d_{i}}{N_{j}}
$$

$151 d_{j}=$ the number of deaths in each state

$152 N j=$ the number of women in reproductive age in each state

153 This method is insufficient to obtain the desired parameter in a small area because there

154 might be small areas not represented adequately in the sample size or not large enough

155 to provide a stable and precise estimate.

156 A synthetic estimate also called an indirect estimate was obtained using the equation:

157

$$
\text { MMRate }_{\text {indirect }}=Y_{\text {indirect }}=X^{\prime} \beta+\epsilon
$$

$158 \varepsilon=$ error term

$159 X^{\prime}=$ Vector of covariates, measured at aggregate/mean for every small area. $X$ is a vector 160 of auxiliary variables that are mortality predictors which would be measured as a mean of 
161 the values for the sub-national levels. So, the mixed model is optimally based on direct and

162 indirect estimates of $\mathrm{Y}$. This prediction is known as best linear unbiased prediction (BLUP)

163 and is a weighted estimate of the direct and indirect estimators which "borrows

164 strength/information" from related areas and groups. This information provided from

165 other related areas increases the effectiveness of the sample size, and in return, the

166 precision of the estimate derived.

167 However, the expected value of the $Y_{\text {indirect }}$ then ignores the error term

$168 E\left(Y_{\text {Indirect }}\right)=X^{\prime} \beta$

169 It ignores the diversity (heterogeneity) of all the small areas based on the assumptions of

170 the areas having similar characteristics; it then assumes that the MMRatio is the same.

171 One of the techniques the small area estimation makes use of is the Random effect model

172 also known as the mixed model. This is different from the generalized linear models as it

173 includes all models in the variance components procedure. MIXED model handles

174 correlated data, unequal variances and complicated situations in which units are nested in

175 a hierarchy, for example, data obtained from a sample of respondents from a sample of

176 states and political regions in Nigeria, as in the NDHS data.

177 The mixed model combines the technique of the direct estimator and the indirect

178 estimator to produce what is known as the BEST LINEAR UNBIASED PREDICTION. The Best

179 Linear Unbiased Prediction estimators minimize the Mean Square Error among the other

180 classes of linear unbiased estimators, and it generally does not depend on the normality

181 of the random effects.

182

$$
Y_{\text {mixed }}=\bar{X}^{\prime} \beta+u_{j}+\varepsilon_{i j}
$$


183 where $u_{j}$ is the heterogeneity/diversity across the small areas.

184

185

186

187

188

189

190

191

192

193

194 Hence,

$195 Y_{\text {mixed }}=(S F j) \times$ direct estimator $+(1-S F j) \times$ indirect estimator

196

197 The maternal death counts were treated as the response variable, and region of residence,

198 wealth index, religion and level of education were the covariates in the model and an offset

199 variable, the logarithm of the persons-year exposure.

200

201

202

$$
\begin{aligned}
& u_{j} \sim N\left(0, \sigma_{u}^{2}\right) \\
& \varepsilon_{j} \sim N\left(0, \sigma_{\varepsilon}^{2}\right)
\end{aligned}
$$

$$
Y_{\text {mixed }}=Y_{j B L U P}=\bar{X}_{j}^{\prime} \beta+\gamma\left(\bar{y}_{j}-\bar{X}_{j}^{\prime} \beta\right)
$$$$
=\bar{X}_{j}^{\prime} \beta+\gamma \bar{y}_{j}-\gamma \bar{X}_{j}^{\prime} \beta
$$$$
=\left(\bar{X}_{j}^{\prime} \beta-\gamma \bar{X}_{j}^{\prime} \beta\right)+\gamma \bar{y}_{j}
$$

$$
=\bar{X}^{\prime}{ }_{j} \beta(1-\gamma)+\gamma \bar{y}_{j}
$$

$$
\gamma_{j}=\frac{\sigma^{2}}{\sigma_{u}^{2}+\sigma_{\varepsilon}^{2}}
$$




\section{Results}

\section{Model-based estimates of maternal mortality rates and ratio}

205 For 2008, the estimates for MMRatio ranged from 280 (95\% Cl: $172-457)$ maternal deaths

206 per 100,000 live-births in Lagos to 879 (95\% Cl: 718 - 1075) maternal deaths per 100,000

207 in Nasarawa State for 2008 (Figure 1) and ranged from 95 (95\% Cl: 57 - 158) maternal 208 deaths per 100,000 live-births in Lagos state to 1621 (95\% Cl:1295 - 2029) maternal deaths 209 per 100,000 live-births in Kastina State for 2013 (Figure 2).

210 Table 1 shows the model-based estimates of MMRatio in the Northern states for 2008.

211 Among all the Northern states, Nasarawa had highest MMRatio of 879 (95\% Cl: 718 212 1075) maternal deaths per 100,000 live-births. Adamawa state had the highest MMR of

213709 (95\% Cl: 621 - 810) maternal deaths per 100,000 live-births among the North Eastern

214 states and Kebbi state had the highest among the North Western states with MMR of 780 215 (95\% Cl; 633 -962). Table 2 shows the model-based estimates of the Southern states. 216 Among the states in the Southern geopolitical zones, Lagos recorded the lowest MMR of $217280(95 \% \mathrm{Cl}: 172$ - 457) maternal deaths per 100,000 live-births and Bayelsa State had the 218 highest MMRatio of $832(95 \% \mathrm{Cl}$ : 671 - 1033) maternal deaths per 100,000. Akwa Ibom 219 State in the South South and Enugu State in the South East also had closely high MMRatio 220 of 762 (95\% Cl: 666 - 872) maternal deaths per 100,000 live-births and 768 (95\% Cl:683 221 865) maternal deaths per 100,000 live-births respectively.

222 Table 3 and Table 4 show the model-based estimates of maternal mortality ratio for the 223 Northern and Southern states for 2013 respectively. Katsina State in North Western part 224 and Benue State in the North Central part of Nigeria had the highest MMRatio of 1621 
225 (95\% Cl: 1295 - 2029) and 1257 (95\% Cl: 973 -1625) maternal deaths per 100,000 live-

226 births respectively followed by Bauchi State in the North East with MMRatio of 998 (95\%

$227 \mathrm{Cl}: 845$ - 1179) maternal deaths per 100,000 live-births. However, states like Kaduna in

228 the North West and Taraba states in the North East had relatively lowered MMRatio of

229267 (95\% Cl: 213 - 334) and 317 (95\% Cl: 332 -414) maternal deaths per 100,000 live-

230 births.

231 Figure 1 and 3 gives insight into how each state in the country fared compared to the

232 national estimates of 545 maternal deaths per 100,000 live-births from the NDHS 2008

233 and 576 maternal deaths per 100,000 live-births. The observation for 2008 is that about

234 half of the 36 states and the FCT falls below and borderline the estimates published by the

235 Nigeria DHS, while the other half of the states have MMR estimates higher than the

236 published national average. However, in 2013, half of the states have MMR below the

237 published estimates by the Nigeria DHS and the other half have MMR higher than the

238 national estimates by the Nigerian DHS. In figures 2 and 4 spatial geographical variations

239 in the MMR from the model-based method for both 2008 and 2013 are presented

240 respectively. Identical patterns, denoted by color-codes (see figure legend) are seen in the

241 various geo-political zones. The MMRatio levels are similar in clusters in the North and this

242 mirrors what is also observed towards the West and the East. 
246 Table 1: Model-Based Estimate of maternal mortality rates (MMRates) and

\begin{tabular}{|c|c|c|c|}
\hline Region & States & MMRate & MMRatio \\
\hline \multirow[t]{7}{*}{ North Central } & Kogi & $0.09(0.07-0.12)$ & $577(440-756)$ \\
\hline & Niger & $0.13(0.10-0.17)$ & $524(411-668)$ \\
\hline & Abuja & $0.11(0.08-0.14)$ & $704(536$ - 920) \\
\hline & Nasarawa & $0.14(0.12-0.18)$ & $879(718-1075)$ \\
\hline & Benue & $0.09(0.06-0.13)$ & $448(315-640)$ \\
\hline & Kwara & $0.12(0.10-0.16)$ & $718(575-898)$ \\
\hline & Plateau & $0.11(0.09-0.13)$ & $629(524-754)$ \\
\hline \multirow[t]{6}{*}{ North East } & Yobe & $0.15(0.12-0.19)$ & $583(475-715)$ \\
\hline & Borno & $0.14(0.12-0.16)$ & $520(454-595)$ \\
\hline & Adamawa & $0.16(0.14-0.18)$ & $709(621-810)$ \\
\hline & Gombe & $0.15(0.13-0.17)$ & $562(483-653)$ \\
\hline & Bauchi & $0.14(0.12-0.17)$ & $533(452-628)$ \\
\hline & Taraba & $0.14(0.12-0.16)$ & $687(599-788)$ \\
\hline \multirow[t]{7}{*}{ North West } & Katsina & $0.14(0.12-0.17)$ & $551(467-649)$ \\
\hline & Jigawa & $0.18(0.15-0.22)$ & $728(595-892)$ \\
\hline & Kano & $0.16(0.12-0.21)$ & $604(459-794)$ \\
\hline & Kaduna & $0.12(0.10-0.14)$ & $541(453-646)$ \\
\hline & Kebbi & $0.17(0.14-021)$ & $780(633-962)$ \\
\hline & Sokoto & $0.19(0.16-0.22)$ & $662(553-793)$ \\
\hline & Zamfara & $0.17(0.14-0.20)$ & $646(540-773)$ \\
\hline
\end{tabular}


249 Table 2: Model-Based Estimate of maternal mortality rates (MMRates) and

\begin{tabular}{|c|c|c|c|}
\hline Region & States & MMRate & MMRatio \\
\hline \multirow[t]{5}{*}{ South East } & Anambra & 0.06 (0.04 -0.07) & $331(255-430)$ \\
\hline & Enugu & $0.10(0.09-0.12)$ & $768(683-865)$ \\
\hline & Ebonyi & $0.10(0.08-0.13)$ & $574(467-705)$ \\
\hline & Abia & $0.08(0.07-0.10)$ & $602(504-718)$ \\
\hline & Imo & 0.08 (0.07 -0.10) & $564(480-663)$ \\
\hline \multirow[t]{6}{*}{ South South } & Edo & $0.06(0.05-0.08)$ & $374(287-487)$ \\
\hline & Cross River & $0.09(0.08-0.11)$ & $539(452-643)$ \\
\hline & Akwa Ibom & $0.11(0.10-0.13)$ & $762(666-872)$ \\
\hline & Rivers & $0.10(0.08-0.12)$ & $695(568-850)$ \\
\hline & Bayelsa & $0.15(0.12-0.19)$ & $832(671-1033)$ \\
\hline & Delta & $0.08(0.07-0.10)$ & $582(503-674)$ \\
\hline \multirow[t]{6}{*}{ South West } & Oyo & $0.07(0.05-0.08)$ & $367(288-468)$ \\
\hline & Osun & $0.06(0.05-0.08)$ & $502(390-646)$ \\
\hline & Ekiti & $0.09(0.07-0.11)$ & $568(434-742)$ \\
\hline & Ondo & 0.09 (0.07 0 11) & $566(460-697)$ \\
\hline & Lagos & $0.04(0.02-0.06)$ & $280(172-457)$ \\
\hline & Ogun & $0.08(0.06-0.09)$ & $421(336-528)$ \\
\hline
\end{tabular}




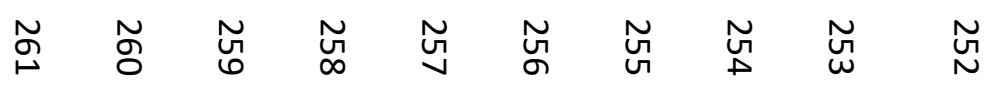

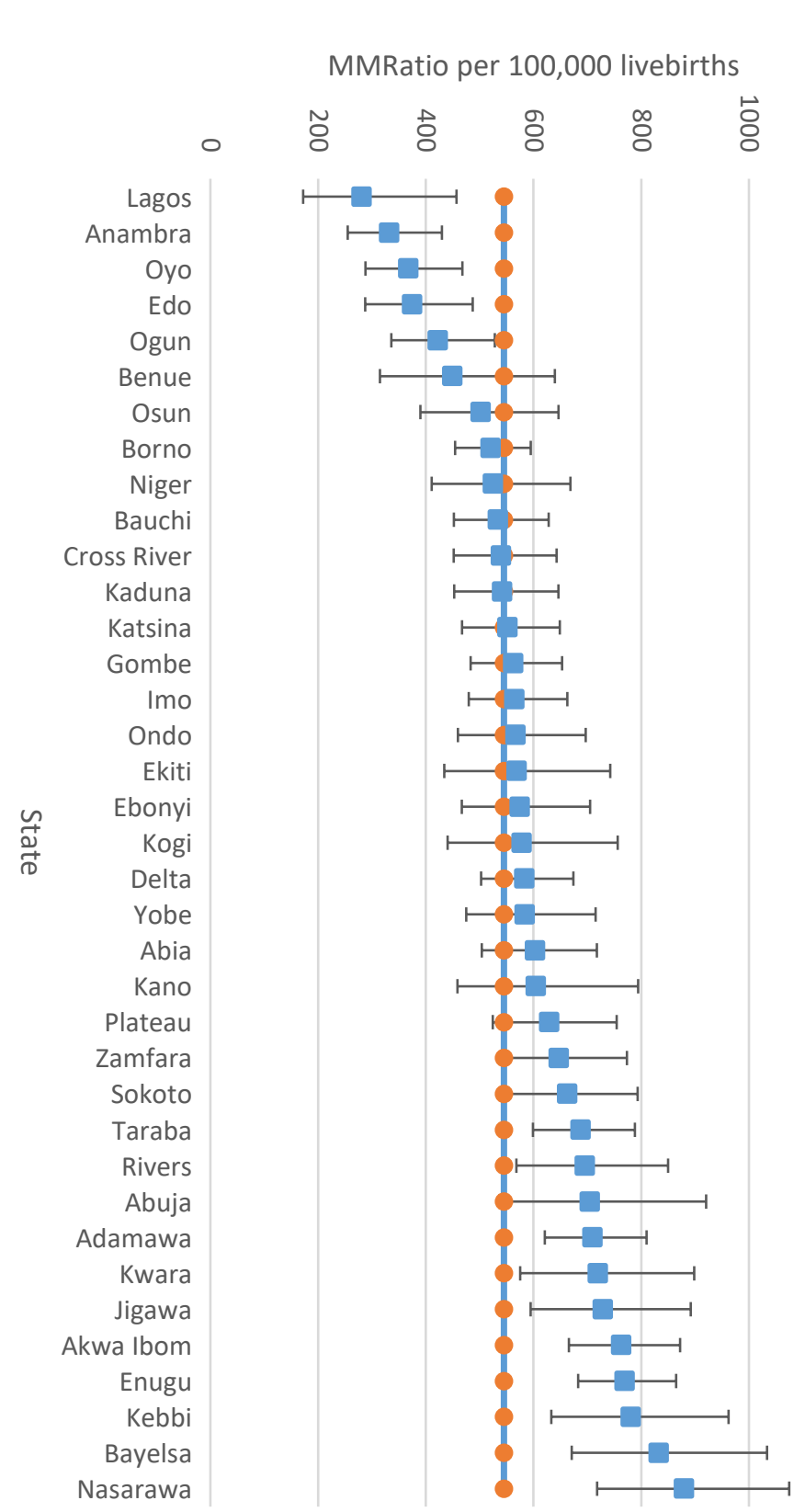

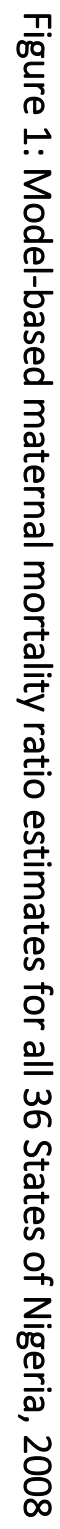


262 Figure 2: Map showing Model-based subnational maternal mortality ratio (MMRatio) estimates,

263 for 36 states and FCT, Nigerian DHS 2008

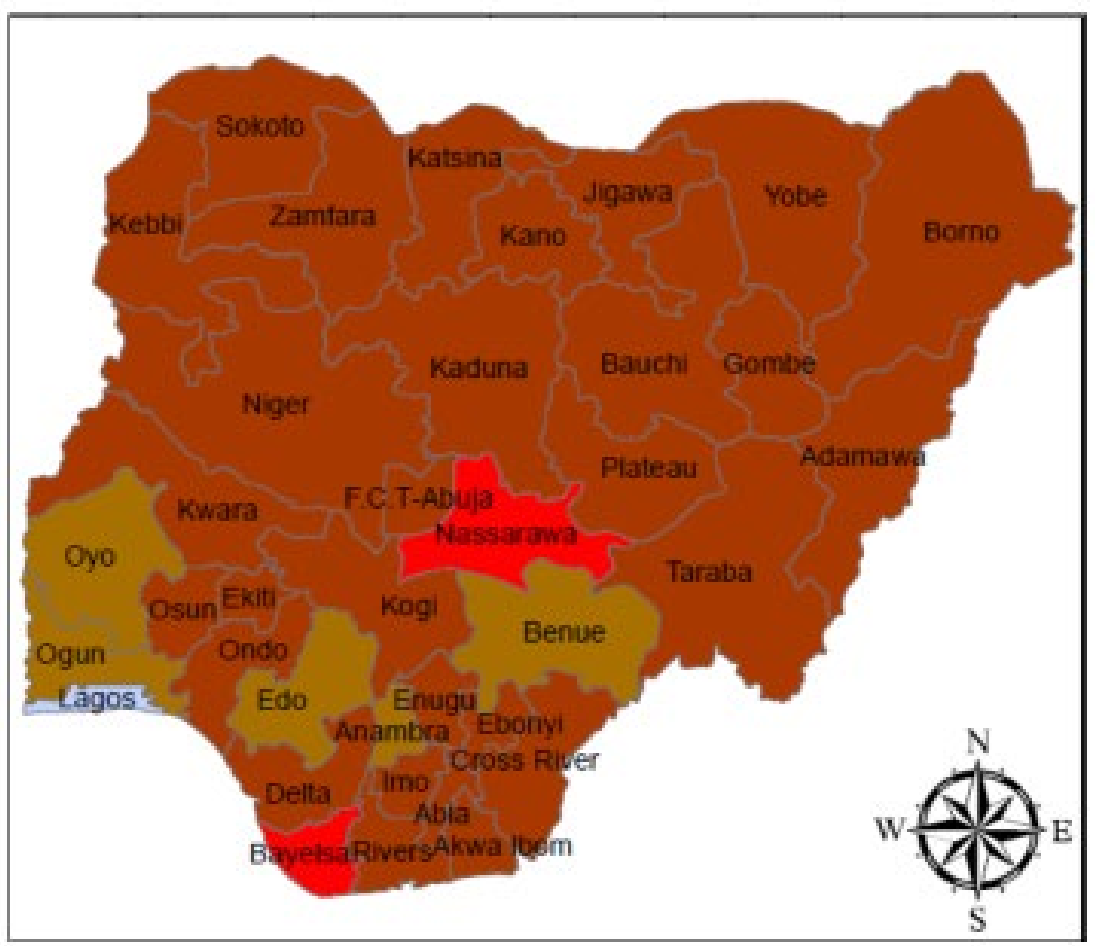

\begin{tabular}{|l|}
\hline \multicolumn{1}{|c|}{ Legend } \\
\hline$\square<100$ \\
\hline $100-300$ \\
$301-500$ \\
$501-800$ \\
\hline$>800$ \\
\hline
\end{tabular}


265 Table 3: Model-based Estimate of maternal mortality rates (MMRates) and maternal mortality 266 ratio (MMRatio) in Northern States Nigeria, 2013

\begin{tabular}{|c|c|c|c|}
\hline Region & States & MMRate & MMRatio \\
\hline \multirow[t]{7}{*}{ North Central } & Kogi & $0.14(0.12-0.17)$ & $572(485-674)$ \\
\hline & Niger & $0.17(0.13-021)$ & $660(525-829)$ \\
\hline & Abuja & $0.13(0.11-0.15)$ & $439(368-525)$ \\
\hline & Nasarawa & $0.11(0.10-0.13)$ & $422(358-497)$ \\
\hline & Benue & $0.21(0.17-0.28)$ & $1257(973-1625)$ \\
\hline & Kwara & $0.14(0.12-0.17)$ & $809(667-982)$ \\
\hline & Plateau & $0.14(0.12-0.16)$ & $514(466-592)$ \\
\hline \multirow[t]{6}{*}{ North East } & Yobe & $0.12(0.10-0.14)$ & $591(505-692)$ \\
\hline & Borno & $0.14(0.11-0.17)$ & $856(689-1062)$ \\
\hline & Adamawa & $0.12(0.10-0.14)$ & $494(415-587)$ \\
\hline & Gombe & $0.13(0.11-0.15)$ & $691(607-788)$ \\
\hline & Bauchi & $0.20(0.17-0.24)$ & $998(845-1179)$ \\
\hline & Taraba & $0.08(0.08-0.09)$ & $371(332-414)$ \\
\hline \multirow[t]{7}{*}{ North West } & Katsina & $0.23(0.19-0.29)$ & $1621(1295-2029)$ \\
\hline & Jigawa & $0.18(0.14-0.22)$ & $960(766-1204)$ \\
\hline & Kano & $0.08(0.08-0.14)$ & $325(193-545)$ \\
\hline & Kaduna & $0.08(0.06-0.10)$ & $267(213-334)$ \\
\hline & Kebbi & $0.12(0.10-0.15)$ & $584(490-696)$ \\
\hline & Sokoto & $0.14(0.11-0.16)$ & $963(810-1146)$ \\
\hline & Zamfara & $0.11(0.09-0.13)$ & $480(385-599)$ \\
\hline
\end{tabular}


267 Table 4: Model-based Estimate of maternal mortality rates (MMRates) and maternal mortality

268 ratio (MMRatio) in Southern States Nigeria, 2013

\begin{tabular}{|c|c|c|c|}
\hline Region & States & MMRate & MMRatio \\
\hline \multirow[t]{5}{*}{ South East } & Anambra & $0.09(0.07-0.11)$ & 632 (517 774) \\
\hline & Enugu & $0.09(0.07-0.10)$ & $503(430-588)$ \\
\hline & Ebonyi & $0.08(0.07-0.09)$ & 641 (541 -760) \\
\hline & Abia & $0.13(0.11-0.15)$ & $915(784-1068)$ \\
\hline & Imo & $0.07(0.06-0.08)$ & 433 (375 -499) \\
\hline \multirow[t]{6}{*}{ South South } & Edo & $0.11(0.08-0.13)$ & $691(554-862)$ \\
\hline & Cross River & $0.08(0.07-0.09)$ & $620(542-710)$ \\
\hline & Akwa Ibom & $0.15(0.14-0.17)$ & $939(826-1066)$ \\
\hline & Rivers & $0.07(0.05-0.08)$ & $483(387-603)$ \\
\hline & Bayelsa & $0.16(0.13-0.20)$ & 1169 (937-1458) \\
\hline & Delta & $0.07(0.06-0.09)$ & $454(388-532)$ \\
\hline \multirow[t]{6}{*}{ South West } & Oyo & $0.04(0.03-0.05)$ & $262(186-386)$ \\
\hline & Osun & $0.08(0.07-0.10)$ & $620(508-759)$ \\
\hline & Ekiti & $0.11(0.09-0.14)$ & $681(552-842)$ \\
\hline & Ondo & $0.09(0.07-0.10)$ & $624(523-743)$ \\
\hline & Lagos & $0.01(0.01-0.02)$ & $95(57-158)$ \\
\hline & Ogun & $0.08(0.07-0.10)$ & $453(378-543)$ \\
\hline
\end{tabular}




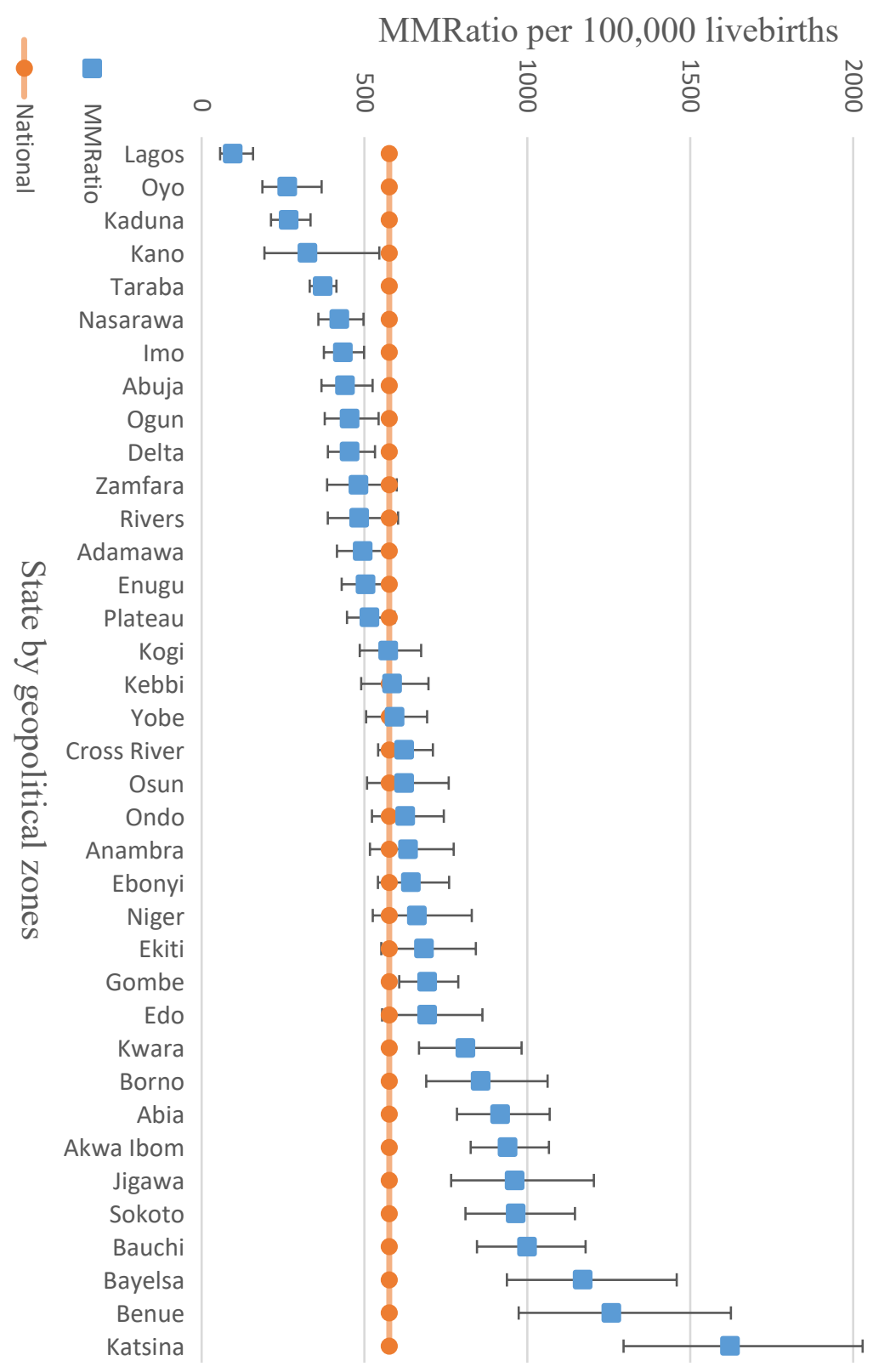

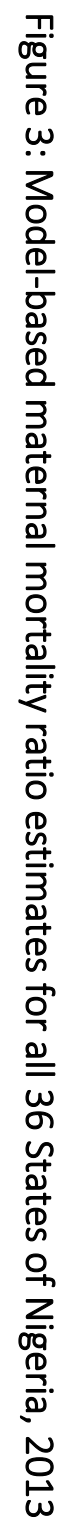


271 Figure 4 : Map showing Model-based sub-national maternal mortality ratio (MMRatio) estimates,

272 for 36 states and FCT, Nigerian DHS 2013.

273

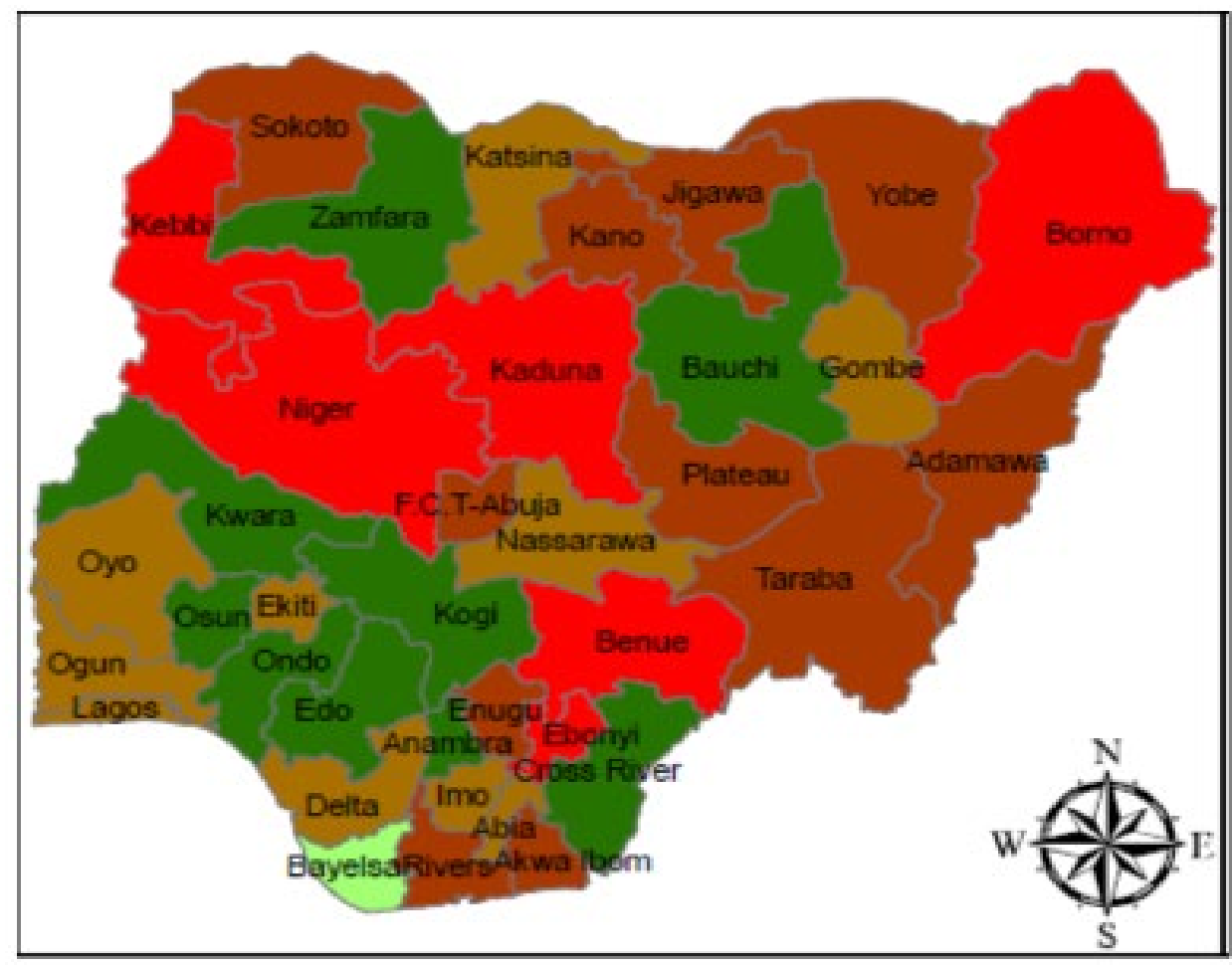

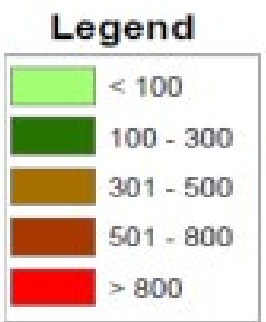


274 Table 5: Model-based Estimate of maternal mortality rates (MMRates) and maternal mortality

275 ratio (MMRatio) in Northern States Nigeria, 2018

\begin{tabular}{|c|c|c|c|}
\hline Region & States & MMRate & MMRatio \\
\hline \multirow[t]{7}{*}{ North Central } & Kogi & 0.14 & $2308(2247-2314)$ \\
\hline & Niger & 0.09 & $2464(2456-2654)$ \\
\hline & Abuja & 0.21 & 1206 (1072 -1442) \\
\hline & Nasarawa & 0.14 & $949(929-954)$ \\
\hline & Benue & 0.09 & $626(617-628)$ \\
\hline & Kwara & 0.14 & $591(540-614)$ \\
\hline & Plateau & 0.12 & $862(844-992)$ \\
\hline \multirow[t]{6}{*}{ North East } & Yobe & 0.10 & $480(445-494)$ \\
\hline & Borno & 0.10 & $357(291-394)$ \\
\hline & Adamawa & 0.12 & $659(614-687)$ \\
\hline & Gombe & 0.13 & $811(743-862)$ \\
\hline & Bauchi & 0.10 & $651(601-788)$ \\
\hline & Taraba & 0.11 & $420(377-536)$ \\
\hline \multirow[t]{7}{*}{ North West } & Katsina & 0.07 & $188(150-199)$ \\
\hline & Jigawa & 0.10 & $173(70-227)$ \\
\hline & Kano & 0.06 & $233(149-281)$ \\
\hline & Kaduna & 0.07 & $326(273-346)$ \\
\hline & Kebbi & 0.10 & $665(617-689)$ \\
\hline & Sokoto & 0.12 & $320(294-328)$ \\
\hline & Zamfara & 0.09 & $809(761-830)$ \\
\hline
\end{tabular}


277 Table 6: Model-based Estimate of maternal mortality rates (MMRates) and maternal mortality

278 ratio (MMRatio) in Southern States Nigeria, 2018

\begin{tabular}{|c|c|c|c|}
\hline Region & States & MMRate & MMRatio \\
\hline \multirow[t]{5}{*}{ South East } & Anambra & 0.09 & $667(645-799)$ \\
\hline & Enugu & 0.12 & 681 (649- 685) \\
\hline & Ebonyi & 0.11 & 831 (803-937) \\
\hline & Abia & 0.14 & $886(837-971)$ \\
\hline & Imo & 0.10 & $969(928-1068)$ \\
\hline \multirow[t]{6}{*}{ South South } & Edo & 0.15 & $3719(3683-3725)$ \\
\hline & Cross River & 0.16 & $1872(1862-1974)$ \\
\hline & Akwa Ibom & 0.13 & $890(859-1094)$ \\
\hline & Rivers & 0.09 & $1083(1064-1188)$ \\
\hline & Bayelsa & 0.26 & $444(414-647)$ \\
\hline & Delta & 0.12 & $1735(1658-1857)$ \\
\hline \multirow[t]{6}{*}{ South West } & Oyo & 0.10 & $323(309-423)$ \\
\hline & Osun & 0.13 & $895(797-1025)$ \\
\hline & Ekiti & 0.18 & $943(508-759)$ \\
\hline & Ondo & 0.15 & $1059(1046-1163)$ \\
\hline & Lagos & 0.07 & $546(503-644)$ \\
\hline & Ogun & 0.13 & $13(12-15)$ \\
\hline
\end{tabular}

279

280

281 


\section{Discussions}

283 The study has successfully provided plausible estimates of $\mathrm{MM}$, highlighting the critical areas

284 where maternal mortality rates and ratios are highest in the major sub-populations in Nigeria.

285 Prior to this research, attempts have not been made at using the widely accepted Nigerian

286 Demographic Health Survey datasets to generate disaggregated rates for MM in Nigeria. There

287 were arguments also on the magnitude of mortality among women of reproductive age in Nigeria.

288 This study has ascertained the number of maternal deaths observed in each state in Nigeria. The

289 findings show that MMR in Nigeria has not decreased significantly. It was in fact noticed that there

290 was a slight spike in the estimates of MMR from the 2013 datasets as compared to the 2008

291 datasets and the percentage of maternal deaths increased across the three surveys. MM was

292 relatively lower in the Southern part of Nigeria compared to the Northern regions. The South West

293 experienced a slight increase in MMRatio of about 4.8\% from 2008 to 2018. However, the

294 Mortality trends declined about 18\% in the North West and 54.2\% in the South east from 2008 to

2952018.

296 Also, although the Northern region had a higher burden of MM, a few states contributed to the

297 burden of MM reported in the various geo-political regions. For instance, in 2008, Taraba state in

298 the North East and Kaduna and Zamfara states in the North West, contributed largely to the

299 MMRatio of the Northern region compared to other states in the same region. Ebonyi state in the

300 South East and Akwa Ibom State in the South South also had MMRatio that were as high as those

301 observed in the Northern parts of the country. Similarly in 2013, Niger state in the North Central,

302 Borno state in the North East and Kaduna and Kebbi states in the North West contributes largely

303 to the high magnitude of MMR for the Northern states. Although the Southern states had lower 
304 level of MM compared to the states in the North, Ebonyi state in the South East and Akwa Ibom 305 in the South South had relatively high MMRatio as well. This is one of the advantages of this study; 306 further investigation has been made to ensure that each state in the geo-political region is 307 accounted for, to reveal the magnitude of burden they contribute to each region. The observed 308 differences in MM between the various states mirrors inequalities that has been observed in other 309 developed countries (15). These states' estimates also differ greatly from hospital-based studies 310 in the various states in the country, which are relatively high (additional table 1). This resonates 311 with a previous study in Malawi (16). This highlights possible political will issue and administrative

312 lag in commitment to the health services of individual states. This trickles to the allocation of 313 resources from the central pool to address the healthcare needs of each state. If there are no 314 small area sub-national estimates of mortality indices, in this case $\mathrm{MM}$, and resources are being 315 allocated to each state equally or based on other indicators other that the burden of mortality and 316 monitored and evaluated healthcare needs, then, the real high risk areas will be neglected. This 317 might in turn cause the heavy inequality in the $\mathrm{MM}$ experience of women in neighbouring states 318 within the same geographical locations. In addition, the Northern region has states with high 319 fertility in the country. This means that women of reproductive years are more exposed to the 320 risk of child-bearing in these regions. It is also known that these regions are socially conservative 321 and have practices of early girl- marriages most especially in their rural regions, which can be found 322 largely in northern areas compared to the south (17).

323 In comparison with sub-national MM estimates, findings from this study suggests that facility324 based estimation of MMR, are not substantive representative of these states in which they were 325 carried out. These studies might have over reported the phenomenon, in that it is concentrated 
326 for women that were able to access health care at the clinics where the study was carried out. This

327 leaves out other deaths that occur at home, that could not reach the health care centres or

328 hospitals, and in fact the deaths that were measured might just be emergencies that were rushed

329 into the clinics. Hospital based MMR is rather influenced by a delay in the health seeking behaviour

330 of the women, It can be concluded that facility-based estimates are unacceptably high. Also,

331 worthy to be observed is that these model-based estimates slightly differs from the set of

332 estimates presented by the Institute for Health Metrics and Evaluation (IHME) of the University of

333 Washington in Seattle. Their regression model differed from the UN Interagency with the use of

334 more AIDS or AIDS-related deaths in to the regression model used in obtaining the MMRatio. The

335 IHME estimated maternal deaths to be 342,900 compared to the UN estimates of 358,000

336 maternal deaths. This was used to obtain IHME estimates of 251 per 100,000 live-birth (range 221-

337 289) and UN estimates was 260 (range 200-370). According to Abouzahr (11), these estimates

338 differ in the statistical methods used in deriving the parameters and does not necessarily mean

339 one is superior to the other. While the UN estimates used Gross National Income (GNI) as a

340 covariate in their analysis, as well as general fertility rate and proportion of deliveries attended to

341 by skilled birth attendants, in addition the IHME covariates included total fertility rate, HIV zero-

342 prevalence, neonatal mortality, age-specific female education as well as age. Although still birth

343 attendant was included in the IHME analysis, it was not an addition of the predictive validity of the

344 estimates of MM. It is difficult to judge one method as superior to another as the statistical models

345 are rather descriptive than explanatory in nature. Hence, it will suffice to say experts in various

346 countries study county specific situation and data availability to solve issues of estimates for policy

347 decision making. For this study, the Empirical Bayesian Method for small area estimates works 
348 perfectly in Nigerian. This approach centres the estimates around an average by borrowing

349 information within the population to generate a refined estimates with assumptions suitable for

350 small area estimations. This is a major strength for the small area estimation technique utilizing

351 the empirical Bayesian method. Furthermore, the estimates from this method yielded a narrower

$35295 \%$ confidence intervals for generated estimates.

353

354 In order to tackle high MM in Nigeria, sub-national disparities need to be addressed. This can be

355 urban-rural, geo-political region and even the various states' context. This is beside the

356 concentrated effort made at the central government level. Socio-economic and health

357 development imbalances impede the progress of a country's global or public health improvement.

358 If there are left behind groups in a population, achieving any of the sustainable goals will be

359 sabotaged by huge spatial inequalities. The disaggregation of the data into the sub-population as

360 adopted in this study has provided plausible estimates with which MM in Nigeria's sub-population

361 can be described, monitored and curbed. At this stage, in Nigeria, level of MM produced in this

362 study for each sub-population might not be precise estimates, but it is sufficient to raise the

363 consciousness of the government and policy makers to the magnitude in various types of places

364 of residence, geo-political zones and states. For instance, estimates bordering between 300-700

365 per 100,000 might be given same policy responses, however, sub-population with estimates

366 higher than that are definitely red flagged areas. Evidence-based decisions clearly require reliable

367 estimates, in the absence of which resources will be wasted undetected. This has provided

368 researched evidence for a need to target intervention programmes to the high risks areas like the 
369 North Central, North West and some part of the South-South, where MM is highest and most

370 likely to occur.

371 With increasing demographic transition and change in population dynamics, there is a need to

372 delineate population data to accommodate the heterogeneity of various socio-demographic

373 groups. In Africa, women of reproductive age differ by risks process, urbanization, and geopolitical

374 regions, which provides a challenge for policy implementation. This study has provided estimates

375 that allow for spatial mapping of small area MM experience in Nigeria. This helps for

376 understanding geographical variation and allocating decentralized resources, and policies to curb

$377 \mathrm{MM}$ in sub-national areas with high level of MM. This can also assist social demographers in

378 assessing etiological hypotheses in researching the high-risk areas of MM in Nigeria per state. In

379 many instances, maternal health policies are rather generic; they are extended to all women of

380 reproductive ages and do not account for disparities among most vulnerable and underserved

381 women. Consequently, since challenges and choices differ for women in various environments and

382 socio-economic groups, pooling programs and intervention without adaptive solutions is not as

383 effective. Despite several interventions, Maternal Mortality (MM) remains high in Nigeria. The

384 focus ought then to shift from pushing out programmes and intervention arbitrarily to ensuring

385 maternal health care are evidence-based, tailor-made and available for underserved population

386 that contribute largely to maternal health inequities. It is widely accepted that actions that

387 improve the maternal health of women of reproductive ages not only vary across the age groups

388 but also from countries, communities, and other subpopulations as applies. This makes this study

389 fulfil one of the basic tenants of public health in understanding spatial patterns of health-related

390 problems (18), since public health interventions, even though will be a common thread, actions, 
391 programmes for each subpopulation should be guided by evidence drawn from sound scientific-

392 research (19). This has also in essence crossed the hurdles of unreliable national estimates due

393 to unavailability of CVRS and the rareness of maternal deaths in a statistical sense(20).

394 Reliable sub-population data and estimates on mortality are essential for policy and for planning

395 to monitor the progress and development of a country against set goals. In Nigeria, since Vital

396 Statistics Registration System (CVRS) is unavailable, small area demographic estimation methods

397 can be explored in the interim. This can be by disaggregating population-based data and exploring

398 direct estimation or using model-based approaches $(10,21)$. Within country comparison of

399 demographic estimates, mortality will reveal the dimensions of inequalities in the population.

400 Whiles the availability of the NDHS has brought a rich dataset for demographers to understand

401 the dynamics of population and estimates indices in Nigeria, strengthening the complete CVRS

402 should be a key priority in the country. The registering of births and deaths should be an integral

403 part of the nation's health surveillance culture. In the meantime, more investments should be put

404 in place into the NDHS in enhancing the data quality. Small area datasets need to be collected in

405 national surveys. It might be expensive to have a single survey capture all the information needed,

406 however, data on both health and inequity might be gotten from different sources. For instance,

407 if the data source captures studies for different purposes, it might decide to collect data not only

408 at household level but also put into consideration disaggregation that allows for regional analysis

409 and sub-national estimates which might include, race, ethnicity, economic status etc. Therefore it

410 means sampling must always align with administrative stratification for uniformity. Also, since

411 health intervention programmes are aimed to curb health menaces and also to reduce disparities,

412 regional or state level monitoring of demographic indices will be a useful tool to provide 
413 benchmarking terms. This will ensure that there is appropriate resource allocation according to

414 the magnitude of burden in each sub-national population. This is particularly more effective when

415 the country's health system is decentralized and allows to capture the substantial differences that

416 may occur in the various geographical areas.

417 It is no news that a population-wide intervention would cost more money and resources to

418 implement, hence, focused sub-population-based interventions have been proven to bring about

419 more reduction in $\mathrm{MM}(22)$. Building a sustainable evaluation capacity at the country and state

420 levels will help in the allocation of scarce resources. Evidence-based intervention, programmes,

421 and policies can be made to various states and geo-political zones. This enhances the cases of

422 inclusiveness for rural residents and vulnerable people across the country. There is a need to

423 improve and scale-up demographic estimates for mortality and fertility in different sub-

424 populations in Nigeria exploring the robustness of the Bayesian method and more importantly to

425 strengthen small area demographic estimates in Nigeria and Sub-Saharan Africa at large. The

426 Bayesian method is a rich method that can utilize data from ranges of sources and measure

427 uncertainty in resultant rates. It also has the capability of smoothing data across age, time and

428 space as well as correct mortality data for its incompleteness. More investigation will be required,

429 largely through qualitative researches and probably maternal surveillance audits and autopsies, to

430 determine the factors contributing to a high level of maternity mortality $(\mathrm{MM})$ in the high-risk

431 zones in Nigeria. 


\section{Conclusion}

433 In conclusion, our model-based estimates have provided disaggregation of population data in 434 generating demographic estimates has also been introduced as a plausible means of handling the 435 issues of health disparities across varying sociodemographic groups in the Nigerian population.

436 This is a novel area in demographic research as attention becomes drawn to precision public health

437 to enhance health outcomes through equitable, data-driven policies in population health. This 438 same method can be applied to the under-five mortality and fertility patterns of the various states

439 and geo-political zones in Nigeria. Small area estimation has shown promising possibilities of 440 handling the data inadequacies in some demographic or geopolitical groups that might have 441 insufficient sample sizes for direct estimations of demographic indicators.

442

443

444

445

446

447

448

449

450 
Previous Estimates of Maternal Mortality in Nigeria

\begin{tabular}{|c|c|c|c|c|}
\hline Sources & $\begin{array}{l}\text { Reference } \\
\text { Period }\end{array}$ & Method & $\begin{array}{l}\text { Maternal } \\
\text { deaths }\end{array}$ & MMRatio \\
\hline Medical institution in Western States(23) & 1972 & $\begin{array}{l}\text { Retrospective Hospital-based } \\
\text { Study }\end{array}$ & $\begin{array}{l}\text { Not } \\
\text { available }\end{array}$ & 380 \\
\hline Medical institution in western states (23) & 1973 & $\begin{array}{l}\text { Retrospective Hospital-based } \\
\text { Study }\end{array}$ & $\begin{array}{l}\text { Not } \\
\text { available }\end{array}$ & 470 \\
\hline $\begin{array}{l}\text { Maternal Death Review, University of Ilorin } \\
\text { Teaching Hospital(24) }\end{array}$ & $1972-1983$ & $\begin{array}{l}\text { Retrospective Hospital-based } \\
\text { Study }\end{array}$ & 624 & 450 \\
\hline $\begin{array}{l}\text { University of Nigeria Teaching Hospital, } \\
\text { Nssukka, Enugu State (25) }\end{array}$ & $1991-2000$ & $\begin{array}{l}\text { Retrospective Hospital based } \\
\text { study }\end{array}$ & 182 & 1406 \\
\hline $\begin{array}{l}\text { Ogun State University Teaching Hospital } \\
(26)\end{array}$ & 1988-1997 & $\begin{array}{l}\text { Retrospective Hospital based } \\
\text { study }\end{array}$ & 92 & 1700 \\
\hline $\begin{array}{l}\text { University of Nigeria Teaching Hospital, } \\
\text { Nssukka, Enugu State (25) }\end{array}$ & $1976-1985$ & $\begin{array}{l}\text { Retrospective Hospital based } \\
\text { study }\end{array}$ & 127 & 270 \\
\hline $\begin{array}{l}\text { Research and Statistics Department of the } \\
\text { Ministry of Health; Retrospective study of } \\
\text { information contained in the vital statistics } \\
\text { register in Kano State (27) }\end{array}$ & 2003 & $\begin{array}{l}\text { A non-linear regression model was } \\
\text { fitted to obtain the best temporal } \\
\text { trajectory for the Maternal } \\
\text { Mortality Ratio }\end{array}$ & 4154 & 2420 \\
\hline $\begin{array}{l}\text { University of Port-Harcourt Teaching } \\
\text { Hospital; Retrospective maternity histories } \\
(28)\end{array}$ & 1999 & $\begin{array}{l}\text { Direct (Maternal deaths per total } \\
\text { deliveries) }\end{array}$ & 45 & 2735.6 \\
\hline $\begin{array}{l}\text { Maternal Death Review, Federal Medical } \\
\text { Centre Yola, Adamawa State (29) }\end{array}$ & 2007-2011 & $\begin{array}{l}\text { Retrospective Hospital-based } \\
\text { Study }\end{array}$ & 54 & 636 \\
\hline Lagos University Teaching Hospital (30) & 1989- 1998 & $\begin{array}{l}\text { Retrospective Hospital based } \\
\text { study }\end{array}$ & $\begin{array}{l}\text { Not } \\
\text { available }\end{array}$ & 2920 \\
\hline University Teaching Hospital, Jos (31) & $1985-2001$ & $\begin{array}{l}\text { Retrospective Hospital-based } \\
\text { Study }\end{array}$ & 267 & 740 \\
\hline $\begin{array}{l}\text { Olabisi Onobanjo University Teaching } \\
\text { hospital, Ogun State (32) }\end{array}$ & $2000-2005$ & $\begin{array}{l}\text { Retrospective Hospital based } \\
\text { study-with autopsy record }\end{array}$ & 75 & 2989.2 \\
\hline University of Ilorin Teaching Hospital (33) & 1997-2002 & Retrospective Hospital Survey & 108 & 825 \\
\hline
\end{tabular}




\begin{tabular}{|c|c|c|c|c|}
\hline $\begin{array}{l}\text { Maternal Death Review, Saint Philomena } \\
\text { Catholic Hospital (34) }\end{array}$ & 1996- 2000 & $\begin{array}{l}\text { Retrospective Hospital-based } \\
\text { Study }\end{array}$ & 32 & 454 \\
\hline $\begin{array}{l}\text { Maternal Death Review, Central Hospital, } \\
\text { Benin City, Edo State (35) }\end{array}$ & $1994-2003$ & $\begin{array}{l}\text { Retrospective Hospital based } \\
\text { study }\end{array}$ & 146 & 518 \\
\hline Adeoyo Maternity Hospital, Ibadan (36) & $2003-2004$ & Retrospective Hospital Survey & 84 & 963 \\
\hline University of Uyo Teaching Hospital (37) & $2000-2005$ & Retrospective Hospital Survey & 91 & 2577 \\
\hline University of Nigeria Teaching Hospital (38) & 2004-2008 & $\begin{array}{l}\text { Retrospective Hospital based } \\
\text { study }\end{array}$ & 60 & 840 \\
\hline State Specialists Hospital, Bauchi (39) & 2001-2008 & $\begin{array}{l}\text { Retrospective Hospital based } \\
\text { study }\end{array}$ & $\begin{array}{l}\text { Not } \\
\text { available }\end{array}$ & 1732 \\
\hline $\begin{array}{l}\text { Maternal Death Review, University of } \\
\text { Maiduguri Teaching Hospital (40) }\end{array}$ & 2001-2005 & $\begin{array}{l}\text { Retrospective Hospital-based } \\
\text { Study }\end{array}$ & $\begin{array}{l}\text { Not } \\
\text { available }\end{array}$ & 430 \\
\hline $\begin{array}{l}\text { Retrospective Cross Sectional study, Bidia } \\
\text { and Riverine Urban Slums in Lagos (41) }\end{array}$ & $\begin{array}{l}2010 \text { (but } \\
\text { referring to } \\
\text { years back) }\end{array}$ & Indirect Sisterhood method & $\begin{array}{l}\text { Not } \\
\text { available }\end{array}$ & 1050 \\
\hline $\begin{array}{l}\text { Retrospective Cross sectional study , } 3 \text { Rural } \\
\text { Community in Zaria, Kaduna State (42) }\end{array}$ & $\begin{array}{l}2010 \text { (but } \\
\text { referring to } \\
\text { years back) }\end{array}$ & Indirect Sisterhood method & 328 & 1400 \\
\hline Jos University Teaching Hospital (43) & $2006-2008$ & Prospective Hospital Survey & 56 & 1260 \\
\hline $\begin{array}{l}\text { Maternal Death Review, Federal Medical } \\
\text { Centre Lokoja (44) }\end{array}$ & $2005-2009$ & $\begin{array}{l}\text { Retrospective Hospital-based } \\
\text { Study }\end{array}$ & 44 & 463 \\
\hline $\begin{array}{l}\text { Community; Jigawa, Kastina, Yobe and } \\
\text { Zamfara (45) }\end{array}$ & 2011 & Direct Sisterhood method & 298 & 1271 \\
\hline $\begin{array}{l}\text { Maternal Death Review, Federal Medical } \\
\text { Centre Yola, Adamawa State (29) }\end{array}$ & $2007-2011$ & $\begin{array}{l}\text { Retrospective Hospital-based } \\
\text { Study }\end{array}$ & 54 & 636 \\
\hline $\begin{array}{l}\text { Maternal Death Review, Federal Medical } \\
\text { Centre, Makurdi (46) }\end{array}$ & 2012 & $\begin{array}{l}\text { Retrospective Hospital-based } \\
\text { Study }\end{array}$ & 29 & 1381 \\
\hline All Nigeria (47) & 2013 & Multi-level Regression model & $\begin{array}{l}\text { Not } \\
\text { available }\end{array}$ & 560 \\
\hline $\begin{array}{l}\text { Retrospective Cohort Study, } 24 \text { Local } \\
\text { Governments in Jigawa State (48) }\end{array}$ & 2001 & Indirect Sisterhood method & 300 & 1012 \\
\hline
\end{tabular}


Retrospective Cohort Study, 6 Local

Governments in Kebbi State (17)

2001

Indirect Sisterhood method

204

890

453 


\section{DECLARATIONS}

455 Ethics approval and consent to participate

456 Not applicable - Consent was obtained to use the Demographic and Health Survey Data.

457 Consent for publication

$458 \quad$ Not applicable

459 Availability of data and materials

$460 \quad$ Not applicable

461 Competing interests

462 The authors declare that they have no competing interests

$463 \quad$ Funding

464 Not applicable

465 Authors' contributions

466 OOB designed the study, performed the analysis, and drafted the manuscript for publication. JOA and OA

467 provided scientific advice on the design of the study, data analysis and throughout the preparation of the 468 manuscript. All authors read and approved the manuscript.

469 Acknowledgments

$470 \quad$ Not applicable

471 Authors' information (optional)

472 Not applicable 


\section{References}

474 1. World Health Organization. World Health Day 1998 - Safe Motherhood. Vol. 72, Division of $475 \quad$ Reproductive Health. Geneva, Switzerland; 1998.

$4762 . \quad$ World Health Organization. Trends in Maternal Mortality 2000 to 2017: Estimates by 477 WHO, UNICEF, UNFPA, World Bank Group and the United Nations Population Division. $478 \quad$ Geneva; 2019.

479 3. World Health Organization. Trends in Maternal Mortality : 2000 to 2017. Estimates by 480 WHO, UNCEF, UNFPA, The World Bank and the United Nations Population Division. 2017. $481 \quad 1-119 p$. 
482 4. Merdad L, Hill K, Graham W. Improving the Measurement of Maternal Mortality : The $483 \quad$ Sisterhood Method Revisited. PLoS One. 2013;8(4):1-12.

484 5. Abouzahr C. Making sense of maternal mortality estimates. Working Paper Series No. 11. $485 \quad$ Australia; 2010. Report No.: 11.

486 6. Hill K, Arifeen E, Koenig M, Al-sabir A, Jamil K, Raggers H. How should we measure 487 maternal mortality in the developing world? A comparison of household deaths and 488 sibling history approaches. Bull World Health Organ. 2006;84(3):173-80.

489 7. Graham WJ. Now or never : the case for measuring maternal mortality. Lancet. $490 \quad 2002 ; 359: 701-4$

491 8. Harrison KA. The Struggle to Reduce High Maternal Mortality in Nigeria. Afr J Reprod $492 \quad$ Health. 2009;13(3):9-20.

493 9. WHO UNICEF UNFPA and The World Bank. Trends in Maternal Mortality 1990 to 2010. $494 \quad$ World Health Organization. Geneva; 2012.

495 10. Reza A, Bergen N. Area-based units of analysis for strengthening health inequality 496 monitoring. Bullentin World Heal Organ. 2016;94(August):856-8.

497 11. Abouzahr C. New estimates of maternal mortality and how to interpret them: choice or 498 confusion? Reprod Heal Matters. 2011;19(37):117-28.

499 12. World Health Organization. Trends in Maternal Mortality : 1990 to 2013. Estimates by 500 WHO, UNCEF, UNFPA, The World Bank and the United Nations Population Division. 2014.

501 13. Ahmed S, Hill K. Maternal mortality estimation at the subnational level : a model- based 
method with an application to Bangladesh. Bull World Health Organ. 2011;89:12-21.

503 14. McCarthy J, Maine D. A Framework for Analyzing the Determinants of Maternal Mortality. $504 \quad$ Stud Fam Plann. 1992;23(1):23-33.

505 15. Ronsmans C, Graham WJ. Maternal mortality: who, when, where, and why. Lancet. $506 \quad 2006 ; 368: 1189-200$.

507 16. Beltman JJ, Akker T Van Den, Lam E, Moens M, Kazima J, Massaquoi M, et al. Repetition of 508 a sisterhood survey at district level in Malawi : the challenge to achieve MDG 5. 2011;1-5.

509 17. Gulumbe U, Alabi O, Omisakin OA, Omoleke S. Maternal mortality ratio in selected rural 510 communities in Kebbi State, Northwest Nigeria. BMC Pregnancy Childbirth. $511 \quad 2018 ; 2(18: 503): 1-6$.

512 18. Elliott P, Wartenberg D. Spatial epidemiology: Current approaches and future challenges. $513 \quad$ Environ Health Perspect. 2004;112(9):998-1006.

514 19. Department of Health and Human Services. Evidence-Based Clinical and Public Health : 515 Generating and Applying the Evidence. Secretary's Advisory Committee on National $516 \quad$ Health Promotion \& Disease Prevention Objectives for 2020. 2010.

517 20. Atkinson EJ, Crowson CS, Pedersen RA, Therneau TM. Poisson Models for person-years $518 \quad$ and expected rates. 2008.

519 21. Hosseinpoor AR, Bergen N, Magar V. Monitoring inequality: An emerging priority for 520 health post-2015. Bulletin of the World Health Organization. 2015;93(9).

521 22. Kidney E, Winter HR, Khan KS, Gülmezoglu AM, Meads CA, Deeks JJ, et al. Systematic 
review of effect of community-level interventions to reduce maternal mortality. BMC

$523 \quad$ Pregnancy Childbirth. 2009;9(2):1-9.

524 23. Oduntan OS, Odunlami VB. Maternal mortality in Western Nigeria. Trop Geogr Med. $525 \quad 1975 ; 27(3): 313-216$.

526 24. Adetoro OO. Maternal mortality - a twelve-year survey at the University of Ilorin Teaching

527 Hospital (U.I.T.H.) Ilorin, Nigeria. Int J Gynecol Obstet. 1987;25(2):93-8.

528 25. Okaro J., Umesulike AC, Onah HE, Chukwuali OF, Ezugwu FO, Nweke PC. Maternal 529 Mortality at the University of Nigeria Teaching Hospital, Enugu, Before and After Kenya. $530 \quad$ Afr J Reprod Health. 2001;5(2):90-7.

531 26. Olatunji AO, Sule-odu AO. Maternal mortality at Sagamu, Nigeria--a ten year review ( 5321988 - 1997 ). Niger Postgrad Med J. 2001;8(1):12-5.

533 27. Adamu YM, Salihu HM, Sathiakumar N, Alexander GR. Maternal mortality in Northern $534 \quad$ Nigeria : a population-based study. Eur J Obs Gynecol Reprod Biol. 2003;109:153-9.

535 28. Uzoigwe SA, John CT. Maternal mortality in the University of Port Harcourt Teaching 536 Hospital, Port Harcourt in the last year before the new millennium. Niger Med J.

538 29. Bukar M, Kunmanda V, Moruppa JY, Ehalaiye B, Takai UI, Ndonya DN. Maternal Mortality at Federal Medical Centre Yola, Adamawa State : A Five-Year Review. Ann s Med \&Health $540 \quad$ Sci Res. 2013;3(4):568-71.

541 30. Daramola AO, Banjo AA, Elesha SO. Maternal deaths in the Lagos University Teaching 
Hospital : a ten-year review ( 1989 - 1998 ). Niger Postgrad Med J. 2004;11(4):274-8.

543 31. Ujah I., Aisien JT, Mutihir JT, Vanderjagt DJ, Glew RH, Ugu. Factors Contributing to

544

545

546

547

548

549

550

551

552

553

554

555

556

557

558

559

560

561

Maternal Mortality in North-Central Nigeria : A Seventeen-year Review. Afr J Reprod

Health. 2005;9(3):27-40.

32. Oladapo OT, Lamina MA, Fakoya TA. Maternal deaths in Sagamu in the new millennium : a facility-based retrospective analysis. BMC Pregnancy Childbirth. 2006;6(6):1-7.

33. Aboyeji AP, Ijaiya MA, Fawole AA. Maternal Mortality in a Nigerian Teaching Hospital.pdf. Tropical Doctor; 2007. p. 83-5.

34. Onakewhor JU, Gharoro EP. Changing trends in maternal mortality in a developing country. Niger J Clin Pract. 2008;11(2):111-20.

35. Abe E, Omo-aghoja LO. Maternal Mortality at the Central Hospital, Benin City Nigeria : A Ten Year Review. 2008;12(3):17-26.

36. Olapade E, Lawoyin TO. Maternal Mortality in a Nigerian Maternity Hospital. African J Biomed Res. 2008;11:267-73.

37. Abasiattai A, Umoiyoho A. A 6-Year Review Of Maternal Deaths In A Teaching Hospital In South-South, Nigeria. Internet J Gynecol Obs. 2008;11(1):1-9.

38. Ezugwu EC, Onah HE, Ezugwu FO, Okafor II. Maternal Mortality in a Transitional Hospital. Afr J Reprod Health. 2009;13(4):67-72.

39. Mairiga A., Saleh W. Maternal mortality at the State Specialist Hospital Bauchi , Northern Nigeria . PubMed Commons. East Africa Med J. 2009;86(1):25-30. 
562 40. Bukar M, Audu BM, Takai U. Trends in maternal mortality at University of Maiduguri teaching hospital, Maiduguri, Nigeria - A five year review. Niger Med J. 2010;51(4):147-

564 51.

565

41. Anastasi E, Bernasconi A, Hill O, Adebayo O, Ekanem EE. Estimation of maternal and perinatal mortality in the urban slums of Badia and Riverine in Lagos, Nigeria through the sisterhood method and preceding births technique. Medicos Sin Front. 2010;545.

568 42. Idris H, Tyoden C, Ejembi C, Taylor K. Estimation of Maternal Mortality using the Indirect 569 Sisterhood Method in Three Communities in Kaduna State, Northern Nigeria. Afr J Reprod Health. 2010;14(3):77-82.

571 43. Ngwan SD, Swende TZ. Maternal mortality in JOS Nigeria : A facility based prospective 572 Review. Int J Biol Med Res. 2011;2(2):565-8.

573 44. Alabi OO, Olarunfemi G, Onile TG. The trend in maternal mortality in an upgraded tertiary 574 facility in North. Niger J Med. 2012;21(3):282-9.

575 45. Doctor HV, Olatunji A, Findley SE, Afenyadu GY, Abdulwahab A, Jumare A. Maternal 576 mortality in northern Nigeria: Findings of a health and demographic surveillance system in Zamfara State, Nigeria. Trop Doct. 2012;42(3):140-3.

578 46. Gi A, Ochejele S, Sd N. A Review of Underlying Causes of Maternal Deaths in Benue North 579 Central Nigeria. 2013;1(2):42-7.

47. World Health Organization. Trends in Maternal Mortality : 1990 to 2015. Estimates by WHO, UNCEF, UNFPA, The World Bank and the United Nations Population Division. 2015. 
582 48. Sharma V, Brown W, Kainuwa MA, Leight J, Nyqvist MB. High maternal mortality in Jigawa

583 State, Northern Nigeria estimated using the sisterhood method. BMC Pregnancy

$584 \quad$ Childbirth. 2017;17(163):1-6.

585

586

587

588 